\title{
Friction and Wear Characteristics of TIG Processed Surface Modified Grey Cast Iron
}

\author{
S. N. Pandya, S. K. Nath ${ }^{1}$, and G. P. Chaudhari \\ Department of Metallurgical and Materials Engineering, Indian Institute of Technology, \\ Roorkee, Uttarakhand, India 247667
}

Received 20 March, accepted in revised form 20 June 2009

\begin{abstract}
The surface of gray cast iron has been modified by Tungsten Inert Gas (TIG) process. Welding current of magnitude 25, 35, and 45 amperes have been used to melt the surface of gray cast iron. Microstructural characterization, hardness measurement and dry sliding wear tests have been performed on these modified surfaces. It has been observed that increase in welding current caused the microstructure of grey cast iron to be gradually refined. Graphite flakes segregated between interdendritic regions in the as-received grey cast iron have been completely replaced by a uniform distribution of finer graphite flakes in the matrix. Hardness has been found to increase with increase in welding current. Wear resistance of the gray cast iron also increased with increase in the welding current reaching maximum value for 45 amperes. The increased hardness and wear resistance of these modified surfaces have been explained on the basis of microstructural changes occurring at the surfaces of gray cast iron.
\end{abstract}

Keywords: Gray cast iron; Surface modification; TIG process; Dry sliding wear.

(C) 2009 JSR Publications. ISSN: 2070-0237 (Print); 2070-0245 (Online). All rights reserved.

DOI: $10.3329 /$ jsr.v1i3.2577

J. Sci. Res. 1 (3), 516-527 (2009)

\section{Introduction}

Grey cast iron finds extensive applications in the making of components like gears, links, cylinder block, cylinder head, clutch plate, and piston rings due to its high castability, fair mechanical properties, machinability and wear resistance together with low coefficient of friction [1-3]. Grey cast iron owes these properties due to its typical microstructure which consists of flakes of graphite in the matrix of ferrite / pearlite or both. There is an ever increasing demand for increased wear resistance of grey cast irons for high performance and durability of cylinder liners for diesel engines and heavy gas engines.

Since wear is a surface phenomenon so surface hardening as compared to heat-treating the entire part is more desirable since many castings will crack when subjected to quenching from high temperature. Induction hardening, flame hardening, chemical hardening [4], electron beam hardening [5], laser hardening [6],Tungsten Inert Gas (TIG) welding [7], chill casting are some of the techniques of surface hardening involving

\footnotetext{
${ }^{1}$ Corresponding author: indiafmt@iitr.ernet.in
} 
thermal means. Surface melted grey cast iron by laser technique has shown improved wear resistance compared to heat treated whole component. Recently, TIG welding process has been successfully used to modify surface structure of white cast iron and improving its wear resistance further [7].

In industries, grey cast irons find wider applications than white cast irons. Although there are studies on surface modification of grey cast iron using laser and electron beam welding [8,9], there is very little published work on wear characteristics of TIG processed surface modified grey cast iron. In view of this in the present work, TIG process has been used to obtain surface modified grey cast iron. Grey cast iron used in the present work is a typically slow cooled iron. Dry sliding wear test of surface melted and as-received grey cast iron has been performed on a pin-on-disc tribotester. Wear results have been discussed vis-à-vis microstructure and hardness within the framework of Archard wear law [10].

\section{Experimental Procedures}

Pin samples with dimensions $30 \mathrm{~mm} \times 6 \mathrm{~mm}$ x $6 \mathrm{~mm}$ have been prepared from gray cast iron having composition (wt pet) C-3.1\%, Si-2.7\%, Mn-0.47\%, S-0.09\%, P-0.11\% and Fe-balance. Pin samples have been hardened through rapid solidification using tungsten inert gas (TIG) welding torch with constant current characteristics [11]. A schematic representation of pin sample is shown in Fig.1. A non-consumable tungsten electrode of diameter $2.4 \mathrm{~mm}$ is used for this purpose. The surface melting has been done in an argon atmosphere (with constant argon flow rate of 10 liter $\min ^{-1}$ ). Approximately a layer of 1 $\mathrm{mm}$ depth of surface on both ends of each sample has been melted and solidified. This is shown as dark layers at both ends of the sample in Fig.1. In order to vary the heat input, the welding currents used are 25 amperes (A), $35 \mathrm{~A}$ and 45A. These surface modified samples are now designated as GC2, GC3 and GC4 respectively. Apart from this asreceived gray cast iron samples are designated as $\mathrm{GC} 1$.

After surface modification these samples have been characterized by optical microscopy and hardness measurements. The macrohardness of these samples was measured at a load of $10 \mathrm{Kg}(98.1 \mathrm{~N})$ on a Vickers hardness tester.

Wear tests have been conducted using pin samples having flat surfaces in the contact regions and smoothened corners. Samples have been polished up to a 4/0 grade $(\sim 38 \mu \mathrm{m})$ emery paper and cleaned with acetone to remove dust and grease from the surface of the pin. Dry sliding wear tests have been carried out against a counter face of a hardened and polished disk made of En32 steel having hardness HRC 62. Relative humidity ranged from $15 \%$ to $30 \%$. Room temperature of $25^{\circ} \mathrm{C}$ is maintained throughout the wear test. A pin-on-disc machine, manufactured by DUCOM, Bangalore, India, described earlier [1213 ] is used to carry out the dry sliding wear tests. Schematic representation of the test configuration is shown in Fig. 1.

Pin weight losses have been measured at different intervals of time. Test time intervals used are 10,10,10,15,30, and 60 minutes. Weight loss data have been converted to volume loss using gray cast iron density of $7150 \mathrm{kgm}^{-3}$. All the pin samples have been 
tested at a constant sliding speed of $1 \mathrm{~ms}^{-1}$ and at normal loads of 9.81, 14.71 and $19.62 \mathrm{~N}$. Each test at a given load has been repeated twice, using both surface hardened ends of each sample (Fig.2), and the average data for weight loss after each interval of time have been used for the analysis of friction and wear. Frictional forces are noted at regular intervals of time during the tests. The coefficient of friction, $\mu$, is calculated by dividing the measured friction forces by normal loads. The worn surfaces of all specimens have been examined under scanning electron microscope, LEO $435 \mathrm{VP}$.

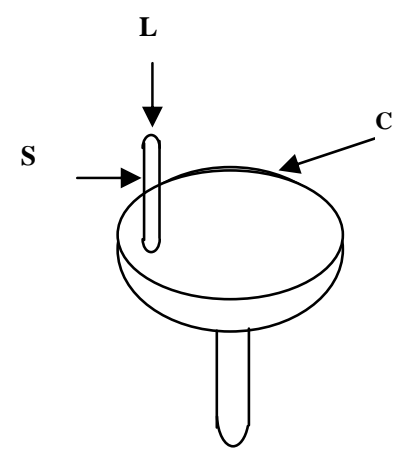

Fig. 1. A pin-on-disc sliding wear test configuration. C: disk; L: load; $\mathrm{S}$ : pin specimen.

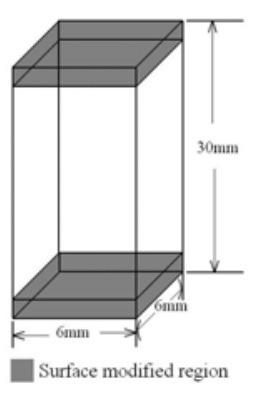

Fig.2. Schematic representation of the pin sample.

\section{Results and discussion}

\subsection{Microstructures}

Optical micrographs of GC1, GC2, GC3 and GC4 samples are shown in Figs. 3a-d respectively. All microstructures are in unetched condition. As-received grey cast iron sample GC1 shows flakes of graphite segregated between interdendritic regions of ferrite (white region). This is a typical microstructure of slowly cooled grey cast iron [1]. Optical micrograph of GC2 sample as shown in Fig. 3b shows a lesser extent of segregation of graphite flakes (black region) in the interdendritic region of ferrite as compared to GC1 sample. Optical micrograph of GC3 sample as shown in Fig. 3c shows uniformly dispersed graphite flakes in the matrix. Optical micrographs of GC4 sample as shown in Fig. 3d shows even more dispersed graphite flakes in the matrix. Some chunks of graphite (black region) are also visible in the microstructures in the samples of GC3 and GC4. Matrix appears white because the sample is in unetched condition. The changes in the microstructure of surface melted samples are attributed to melting of a thin layer of metal by TIG welding process followed by fast cooling. TIG welding is a fusion welding process under the shield of inert gas argon which causes a thin surface layer of metal to melt and subsequently this liquid metal layer solidifies rapidly due to the presence of underlying metal substrate which conducts the heat much faster than dissipation of heat through surrounding atmosphere. Dissolution of graphite (free carbon) in the molten metal 
and subsequent rapid solidification of the molten metal layer, changes the surface microstructure.
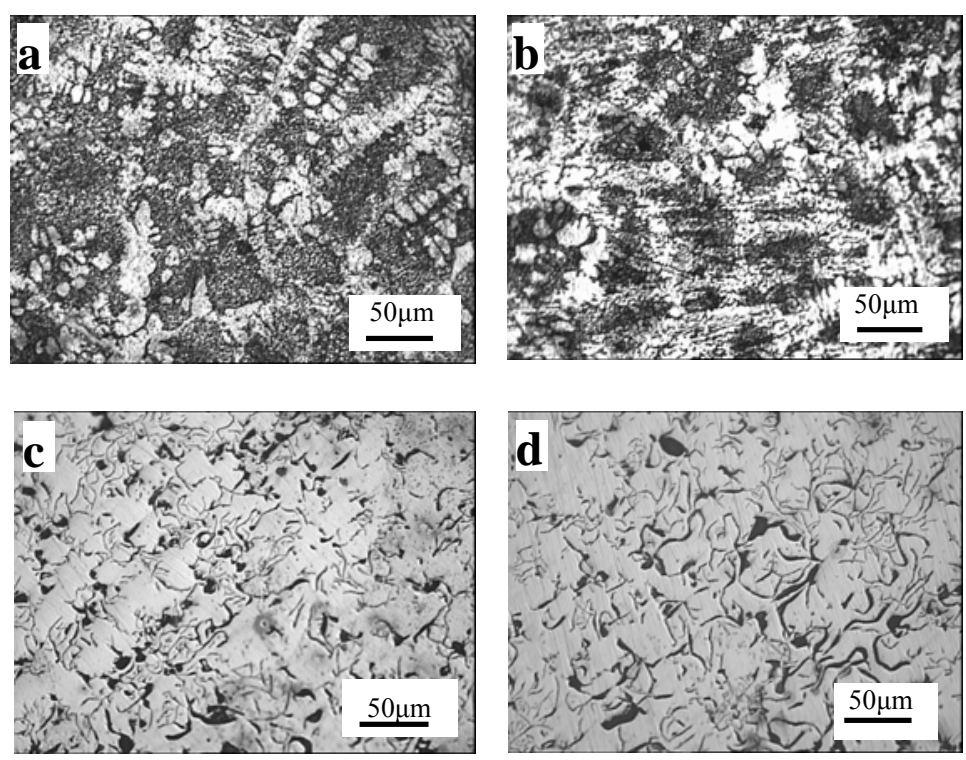

Fig. 3. Optical micrographs of gray cast irons in unetched condition; (a) GC1, (b) GC2, (c) GC3, and (d) GC4. Magnification: 200X.

Microstructure of GC2 sample processed using 25 amperes current shows insufficient refinement of microstructure and the graphite appears segregated similar to GC1. The reason can be attributed to lesser heat input giving rise to thinner melted layer and hence faster solidification because of high rate of heat extraction from thicker substrate. It is observed that welding current of 35 to 45 amperes is required to refine the microstructure as seen in GC3 and GC4 samples. In GC3 and GC4 samples, higher heat input resulted in thicker melted layer causing increased dissolution of graphite flakes. Subsequent cooling is relatively slower as compared to GC2 sample. During solidification the dissolved graphite partially precipitated in a uniform manner.

\subsection{Hardness}

The variation of hardness of cast irons GC1, GC2, GC3 and GC4 with welding current is shown in Fig. 4. It can be observed that unwelded or as-received sample (GC1) has the lowest hardness (187 VHN) compared to the surface modified samples [GC2, GC3, GC4]. It can be further observed that average hardness increases from $204 \mathrm{VHN}$ to $234 \mathrm{VHN} \&$ finally $258 \mathrm{VHN}$ with increasing currents for samples GC2, GC3 and GC4 respectively. This is attributed to higher heat input and hence a thicker layer of molten layer which 
dissolves more graphite and solidifies slowly as its substrate beneath is thinner as compared to GC2 sample. Because of increased dissolution of graphite in the molten iron, during subsequent cooling pearlite content increases in the matrix and hence increase in the hardness of samples. Since the samples are in unetched condition, the pearlite is not visible in the matrix.

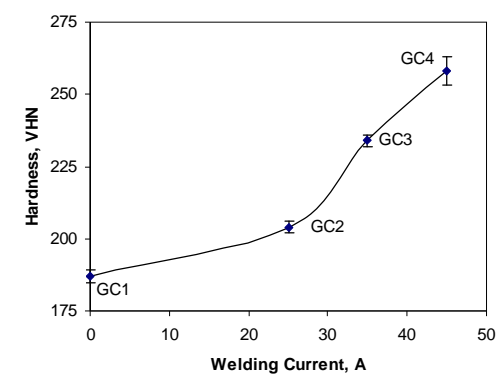

Fig.4. Variation in Hardness of GC Irons with TIG welding current.

\subsection{Dry sliding wear tests}

The variations of cumulative wear volume with sliding distance under different normal loads and at a fixed sliding speed of $1.0 \mathrm{~ms}^{-1}$ for GC1, GC2, GC3, and GC4 samples are shown in Figs. 5a, b, c, d, respectively.
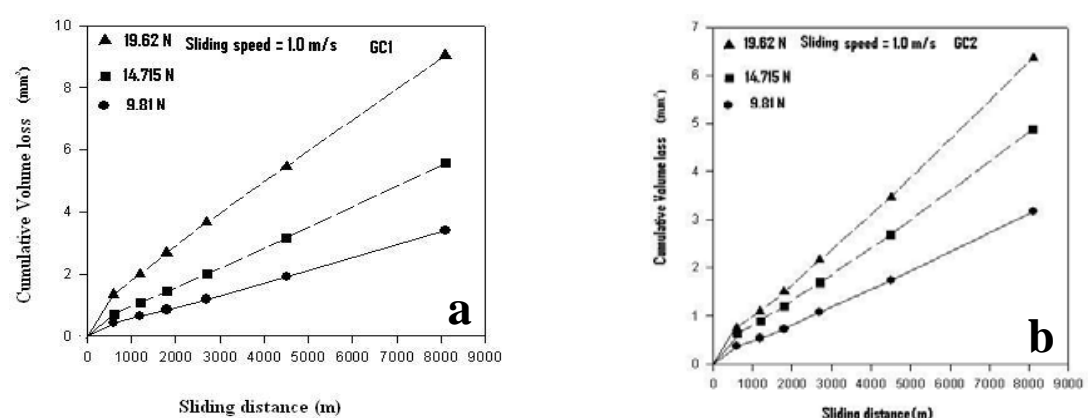

Sliding distance (m)
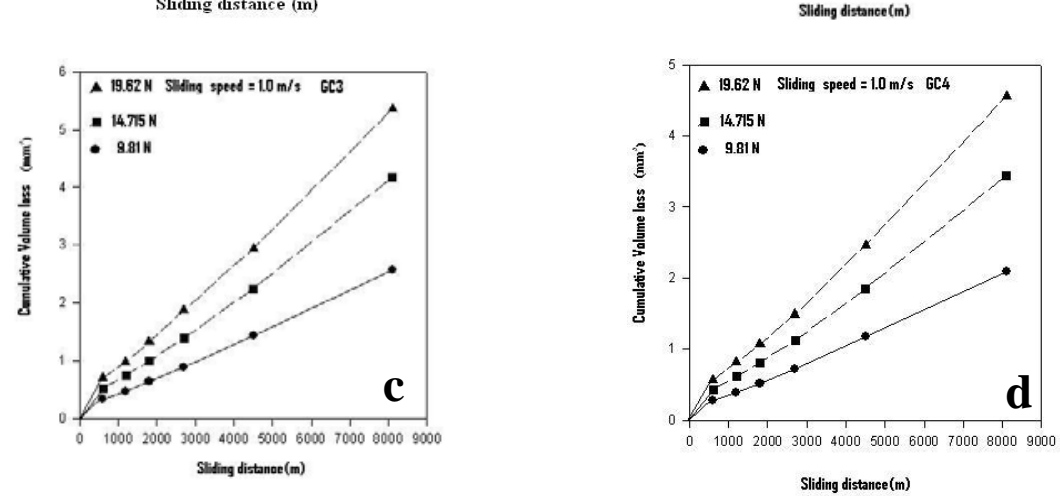

Fig. 5. Cumulative wear volume $\left(\mathrm{mm}^{3}\right)$ with sliding distance at different loads in (a) GC1 (unwelded -as-received), (b) GC2 (welding current 25A), (c) GC3 (welding current 35A), and (d) GC4 (welding current 45A). 
These plots consist of two linear segments. Linear variation of wear volume with sliding distance helps in analyzing the wear data within the frame work of Archard wear equation [10]. It is observed that the slope of the line of second segment changes approximately at sliding distance of $600 \mathrm{~m}$. This is the indication of change from run-in stage to steady-state of wear. These plots further show that as sliding distance increases, the cumulative volume loss increases in all four types of samples. With increase in normal load for a given sliding distance the cumulative volume loss increases in all four types of samples. These observations indicate that they obey Archard law. The following is the expression of Archard wear equation:

$$
V=K W x / H
$$

The amount of wear volume $V$ is generally proportional to the applied load $W$ and sliding distance $x$ and generally inversely proportional to the hardness $H$ of the surface being worn away.

The constant $K$ usually termed Archard wear coefficient or sometimes the coefficient of wear is dimensionless and always less than unity. The dimensionless wear coefficient $K$ is of fundamental importance and provides a valuable means of comparing the severity of wear process in different systems.
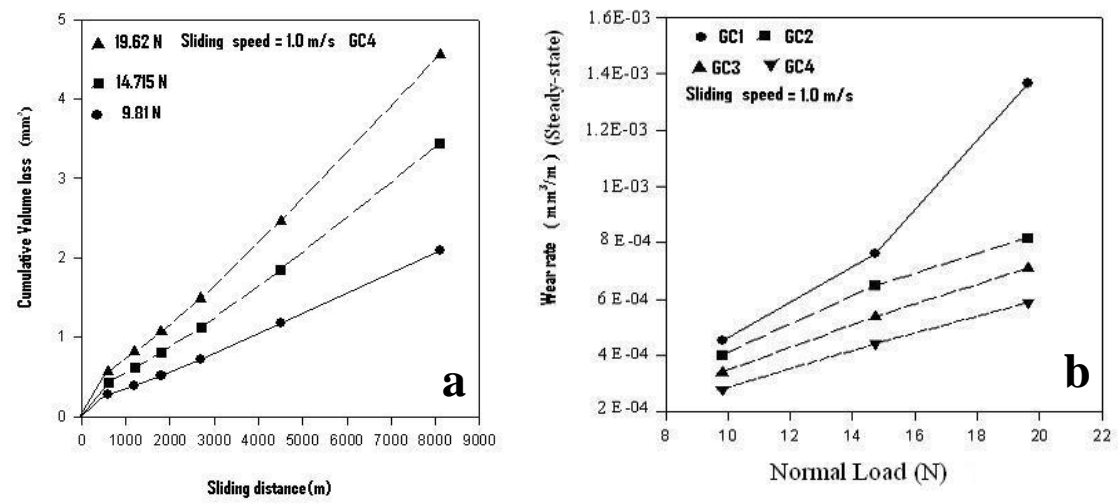

Fig. 6. Variation of wear rates with normal load in GC Irons in the (a) run-in stage of wear, and (b) steady-state stage of wear.

It can be further observed that with increase in TIG welding current [GC1 to GC4], the cumulative volume loss decreases for a given sliding distance and load. This can be explained on the basis of increase in hardness of samples with increase in welding current. The mechanism has been explained above in the hardness section. Wear rates calculated from the slopes of the lines in Figs. 5a-d for run-in and steady-state stage for various normal loads are shown in Fig. 6a and Fig. 6b, respectively. There is lower wear rate in steady-state stage than in run-in stage in all samples. The cause of this higher wear rate in run-in stage as compared to steady-state stage is due to the fact that conformity of the contact surfaces is very low during starting. As sliding distance increases the wear tracks become smooth and wear rate decreases and results in the steady-state stage. 
It can be seen that as normal load increases wear rate increases. For GC1 sample, wear rate $\left(\mathrm{mm}^{3} / \mathrm{m}\right)$ increases from $4.56 \times 10^{-4}$ to $7.61 \times 10^{-3}$ and $1.37 \times 10^{-3}$ as load $(\mathrm{N})$ increases from 9.81 to 14.71 and 19.62 , respectively. For the corresponding loads, wear rate $\left(\mathrm{mm}^{3} / \mathrm{m}\right)$ for GC4 sample is $2.80 \times 10^{-4} 4.43 \times 10^{-4}$, and $5.88 \times 10^{-4}$, respectively. For the same load $9.81 \mathrm{~N}$, wear rates are $4.56 \times 10^{-4}$ and $2.80 \times 10^{-4}$ for samples GC1 and GC4 respectively. The maximum wear rate $\left(\mathrm{mm}^{3} / \mathrm{m}\right)$ is observed in $\mathrm{GC} 1\left(13.7 \times 10^{-4}\right)$ at $19.62 \mathrm{~N}$ load and minimum wear-rate is observed in GC4 $\left(2.80 \times 10^{-4}\right)$ at $9.81 \mathrm{~N}$ load. For GC2 and GC3 samples the wear rates lie in the intermediate ranges.

Archard wear coefficient $K$ for both run-in and steady-state separately, calculated using Eq. (1), is shown in Fig. 6a and Fig. 6b, respectively [12]. The variation of Archard wear coefficient $K$ (for both run-in and steady state) with hardness has been plotted in Fig. 7. These figures show that the wear coefficient $K$ decreases as hardness increases for both run-in and steady-state wear. The variation of wear coefficient $K$ with welding current has been plotted and is shown in Fig. 8. It can be seen that as welding current increases $K$ falls both for run-in and steady-state. Maximum $K$ is observed in GC1 sample $\left(10.26 \times 10^{-5}\right)$ whereas minimum $K$ is $7.47 \times 10^{-5}$ for GC4 sample. Decrease in wear coefficient $K$ with increase in welding current is attributed to the increase in hardness. It is worth noting that Archard wear coefficient $K$ for eutectoid steel is reported to be $1.48 \times 10^{-4}$ [14], whereas the GC4 sample showed comparatively much lower $K$ value.

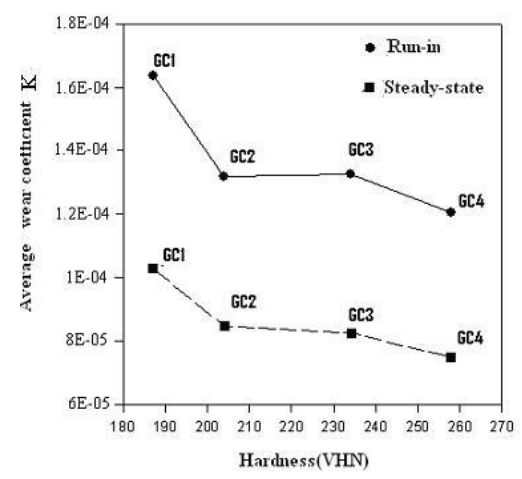

Fig. 7. Variation of average wear coefficient $K$ with hardness in both the run-in and steady-state stage of wear.

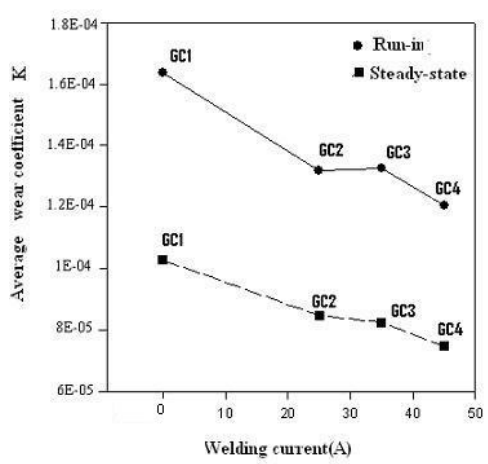

Fig. 8. Variation of average wear coefficient $K$ with welding current $(\mathrm{A})$ in both the run-in and steady-state stage of wear.

The variation of coefficient of friction $\mu$ with sliding distance for GC1,GC2,GC3 and GC4 samples for three normal loads $(9.81 \mathrm{~N}, 14.715 \mathrm{~N}$ and $19.62 \mathrm{~N})$ and a fixed sliding velocity $\left(1.0 \mathrm{~ms}^{-1}\right)$ is shown in Figs. 9a, 9b, 9c and 9d respectively. It can be noticed that $\mu$ in general decreases with increase in sliding distance for a given load. For a given sliding distance, $\mu$ has minimum value for the highest load $(19.62 \mathrm{~N})$. Coefficient of friction $\mu$ has varied from a maximum of 0.63 to a minimum of 0.42 in the present experiment. The lowest $\mu(0.42)$ has been observed in GC4 sample with the maximum $\operatorname{load}(19.62 \mathrm{~N})$. 

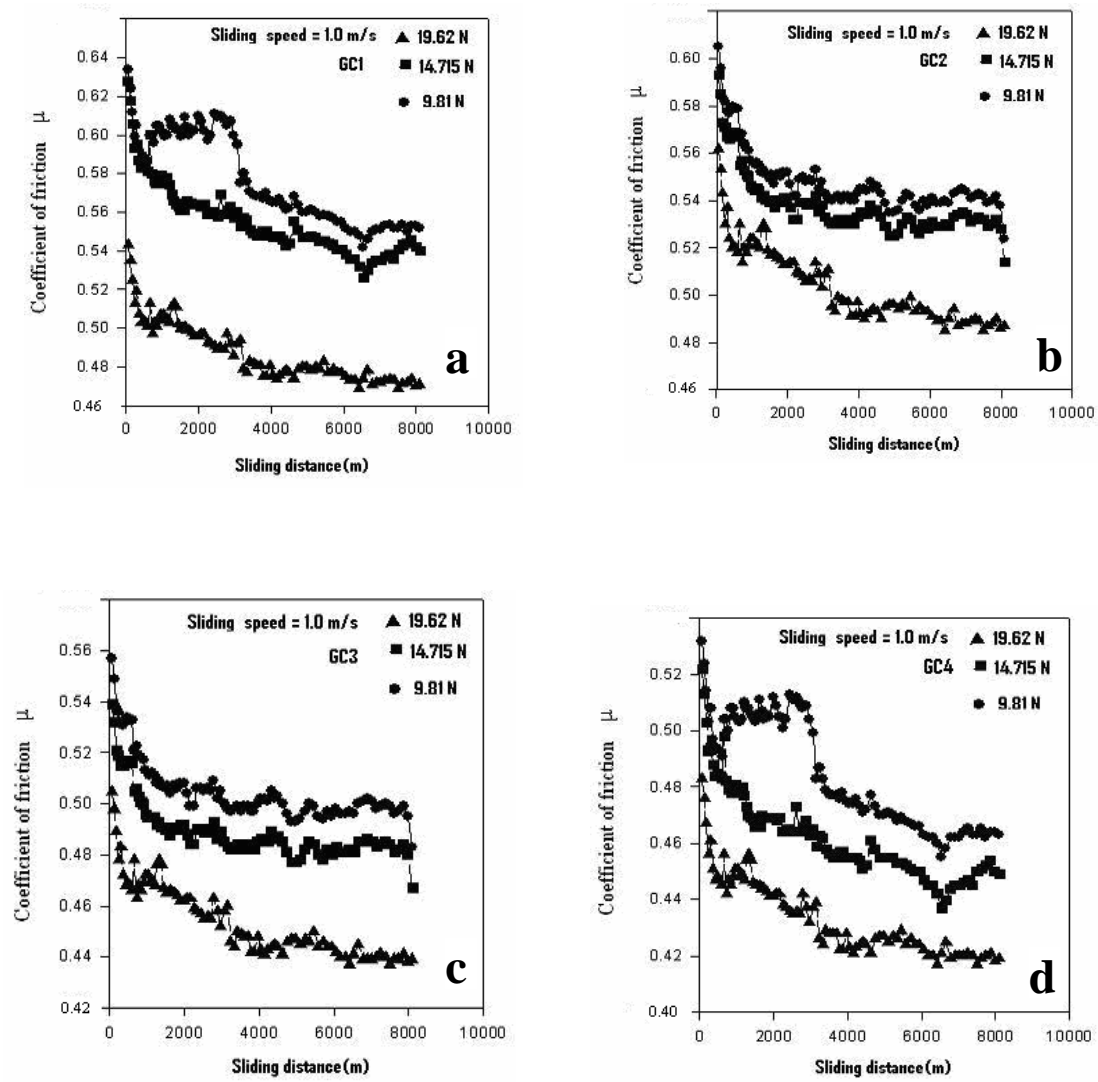

Fig. 9. Variation of coefficient of friction $\mu$ with distance of sliding (m) at different loads in (a) GC1 (unwelded - as-received), (b) GC2 (welding current 25A), (c) GC3 (welding current 35A), and (d) GC4 (welding current 45A).

Average coefficient of friction $\mu$ versus normal load for run-in and steady-state stage of wear for GC1, GC2, GC3 and GC4 samples are shown in Fig. 10a and Fig. 10b, respectively. These figures indicate that average $\mu$ falls with increase in normal load for both run-in and steady-state stage. For a given load average $\mu$ value is a minimum for GC4 iron sample.

Average $\mu$ has also been plotted against hardness for run-in and steady-state stage for four types of samples (GC1, GC2, GC3 and GC4) as shown in Fig. 11. It can be noticed from the figure that $\mu$ decreases as hardness increases for both run-in and steady-state stage. For a given hardness value, average $\mu$ is higher in run-in stage as compared to steady-state stage for all four types of samples. Similarly average $\mu$ has also been plotted against welding current for both run-in and steady-state stage for all four types of iron samples (Fig. 12). It can be observed that the decrease in average $\mu$ with welding current is similar in nature as with the hardness. These changes in frictional behaviour can be 

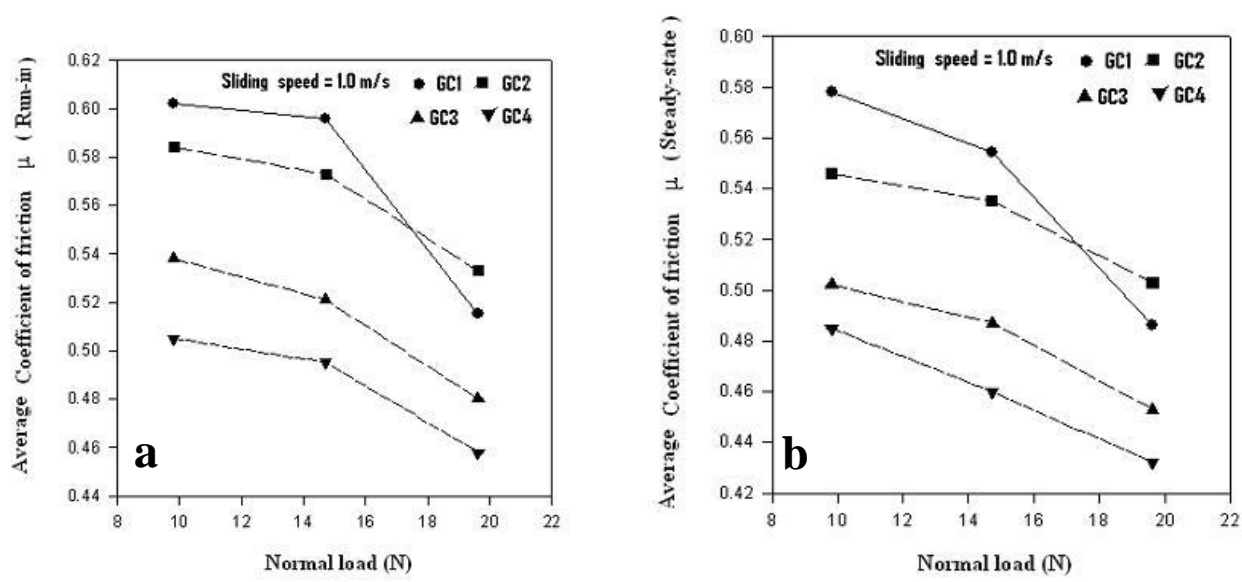

Fig. 10. Variation in average coefficient of friction $\mu$ with load in GC irons in (a) run-in stage, and (b) steadystate stage of wear.

understood by the fact that the hard surface developed due to welding is responsible for lower coefficient of friction [13]. As one knows the higher the hardness of the material the lower is the coefficient of friction [2]. In a given sample, the cause of higher wear rate for higher load as compared to lower load is as per Archard's wear law. The cause of lower coefficient of friction $\mu$ with higher load as compared to lower load for a given sliding speed is attributed to the presence of well compacted transfer layers [7] which consists of mostly iron oxides [12-13] and graphite (Figs. 13a-c to 16a-c). Graphite also helps in reducing coefficient of friction by acting as solid lubricant.

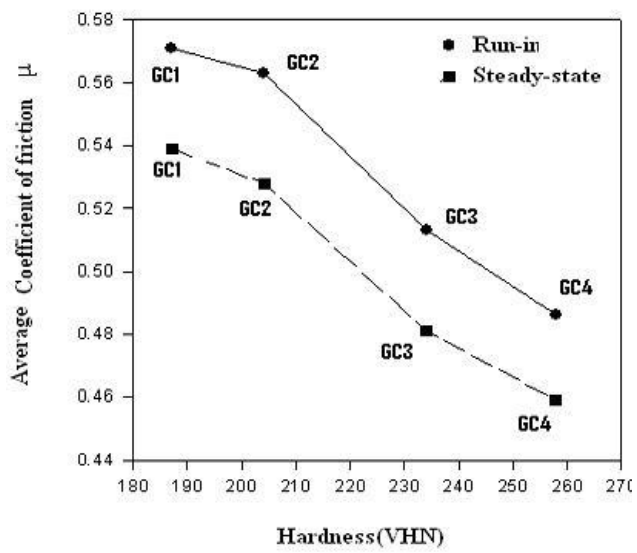

Fig. 11. Average friction coefficient $\mu$ with Hardness (VHN) in both run-in and steady-state stage of wear.

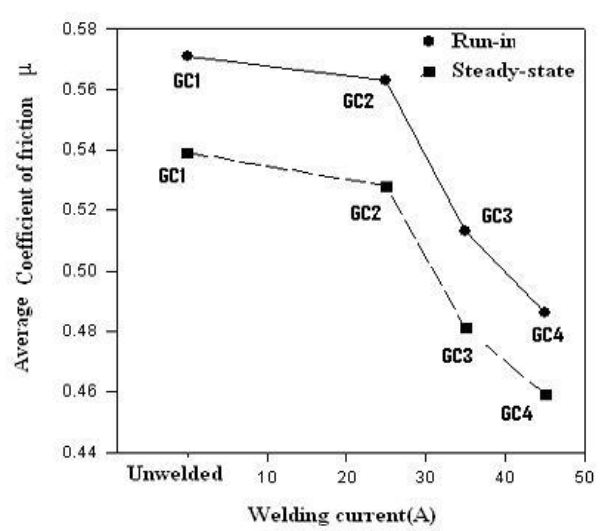

Fig. 12. Variation of average friction coefficient $\mu$ with welding current (A) in both run-in and steady-state stage of wear. 


\subsection{SEM of worn surfaces}

The SEM micrographs of worn surface of sample of GC1 at three normal loads $(9.81 \mathrm{~N}$, 14.715 N and 19.62 N) are shown in Figs. 13a-c. Similarly Figs. 14a-c, 15a-c and 16a-c show the worn surfaces of samples of GC2, GC3 and GC4 irons, respectively.
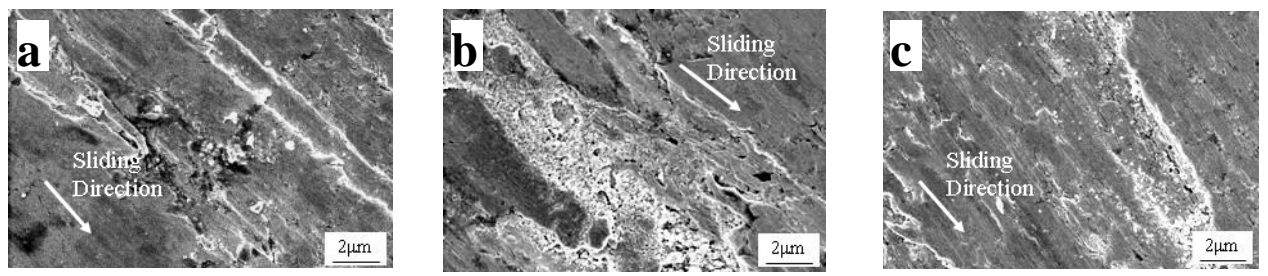

Fig. 13. SEM micrographs of worn surface of GC1 at normal loads of (a) $9.81 \mathrm{~N}$ (b) 14.715 and (c) $19.62 \mathrm{~N}$.
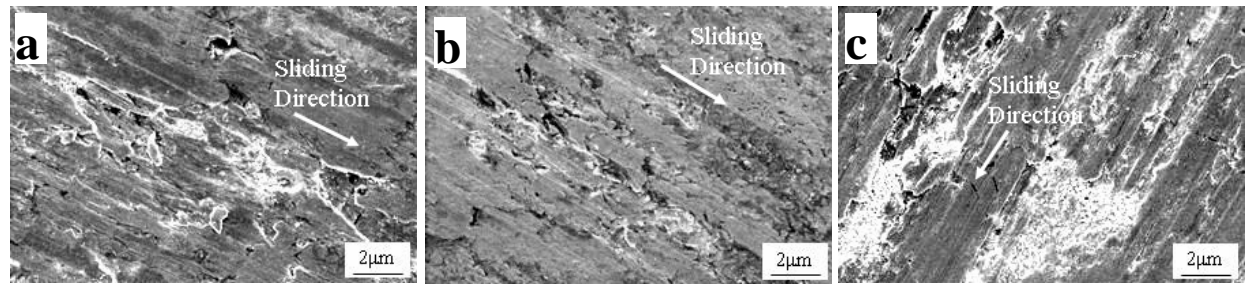

Fig. 14. SEM micrographs of worn surface of GC2 at normal loads of (a) $9.81 \mathrm{~N}$, (b) 14.715 , and (c) $19.62 \mathrm{~N}$.
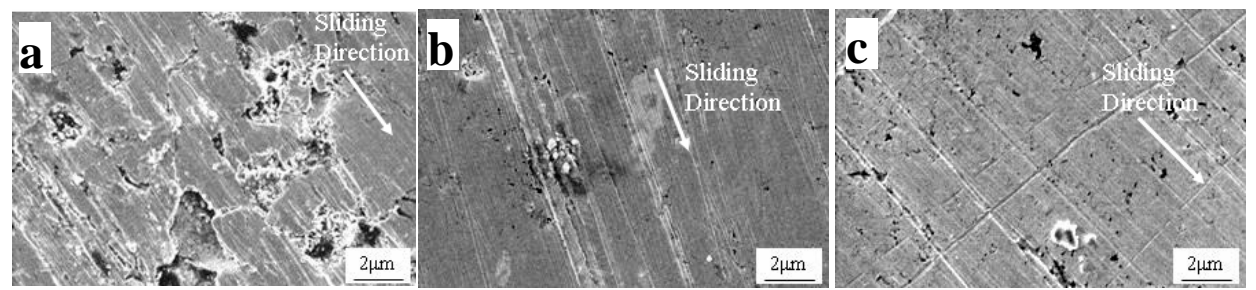

Fig. 15. SEM micrographs of worn surface of GC3 at normal loads of (a) $9.81 \mathrm{~N}$, (b) 14.715, and (c) $19.62 \mathrm{~N}$.
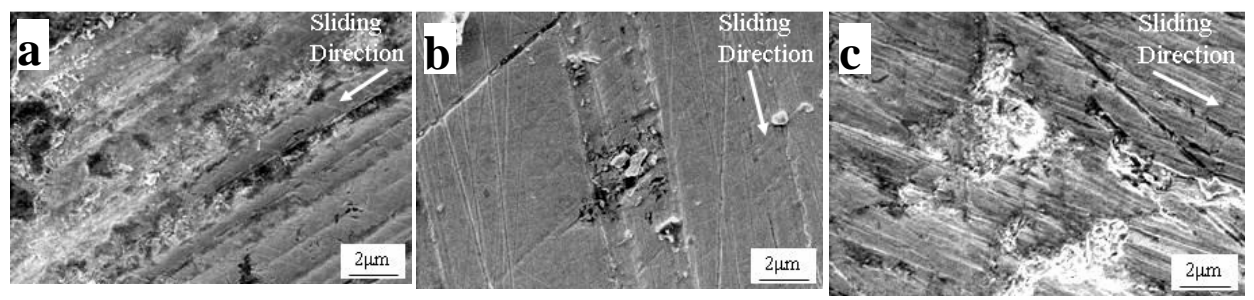

Fig. 16. SEM micrographs of worn surface of GC4 at normal loads of (a) $9.81 \mathrm{~N}$, (b) 14.715 , and (c) $19.62 \mathrm{~N}$. 
It can be observed from these micrographs that for a given load, with the increase in the hardness of the samples, wear tracks have become finer and voids formed due to pullout of graphite (black region) from the matrix are less. At some places compacted layer of oxides (bright region) have been noticed. As discussed earlier, this compacted layer, sometimes also called transfer layer, is very useful in decreasing wear and coefficient of friction by way of decreasing the metal to metal contact between the pin sample and the counter face of the pin-on-disc machine. Usually, this compacted layer consists of iron oxides in case of steel samples [12-13]. Since this is a grey cast iron, it is expected that compacted layer should contain apart from iron oxides some free carbon from the graphite flakes. It is further noticed that at some places porosity (black regions) are also visible.

\section{Conclusions}

The following conclusions can be drawn from the present work:

(1) The TIG welding process is capable of modifying the surface microstructure and hardness of gray cast iron.

(2) With increase in TIG welding current from $25 \mathrm{~A}$, to $35 \mathrm{~A}$ and finally to $45 \mathrm{~A}$, the initial microstructure consisting of flakes of graphite segregated between interdendritic regions of ferrite has been replaced by a structure consisting uniform distribution of finer graphite flakes in the matrix of ferrite and pearlite.

(3) The higher the welding current, the higher is the hardness of the surface of the sample. The maximum hardness of $258 \mathrm{VHN}$ is observed in GC4 (45 Ampere) and minimum hardness of $187 \mathrm{VHN}$ is observed in GC1 (as-received sample). This increase in hardness is attributed to uniform distribution of finer graphite flakes and increase in pearlite content of the matrix. The increase in pearlite content in the matrix has been explained on the basis of dissolution of graphite in the molten iron.

(4) Dry sliding wear behaviour of surface melted grey cast iron has been explained on the basis of linear variation of wear volume against sliding distance. This linear variation is shown in two regions i.e. run-in and steady state. Transition from run-in to steady state has been found at approximately 600 meters of sliding distance.

(5) With increase in welding current the wear rate of the material decreases. In unwelded sample $(\mathrm{GC} 1)$ wear rate $\left(\mathrm{mm}^{3} / \mathrm{m}\right)$ is maximum $13.7 \times 10^{-4}$, whereas the wear rate $\left(\mathrm{mm}^{3} / \mathrm{m}\right)$ is minimum in GC4 sample $\left(2.8 \times 10^{-4}\right)$. This has been again explained on the basis of increased hardness and uniform distribution of graphite flakes.

(6) Maximum coefficient of friction $(\mu)$ value is observed in GC1 sample (0.58) for the load $9.81 \mathrm{~N}$ and minimum $\mu$ has been observed in GC4 sample (0.43) for the load $19.62 \mathrm{~N}$. The decrease in coefficient of friction has been explained on the basis of formation of well compacted layer of iron oxide and graphite on the harder surface which decreases direct metal to metal contact. Graphite also helps in reducing coefficient of friction by acting as solid lubricant. 


\section{References}

1. R.W. Heine, C. R. Loper, Jr and P.C. Rosenthal, Principles of Metal Casting (TMH Ed. 1976).

2. I.M.Hutchings, Tribology, Friction and Wear of Engineering Materials (4th Impression, Arnold, London, 1996).

3. B. Bhushan, Introduction to Tribology (John Wiley \& Sons Inc., New York, 2002).

4. G. Nicoletto, A. Tucci, and L. Esposito, Wear 197, 38 (1996). doi:10.1016/0043-1648(95)06753-1

5. D. Suh, S. Lee., S. J. Kwon, and Y. Koo, Metall. Mater. Trans. 28A, 1499 (1997).

6. P. W. Leech, Wear 113, 233 (1996). doi:10.1016/0043-1648(86)90123-7

7. A. W. Orlowicz and A. Trytek, Wear 254, 154 (2003). doi:10.1016/S0043-1648(02)00301-0

8. J. Straus, L. Szylar, W. Golebiewski, Key Engineering Materials 46-47, 369 (1990). doi:10.4028/www.scientific.net/KEM.46-47.369

9. N.M. Alexandrova, S.Yu. Mackushev, V.E. Melnikov, Acta Physica Polonica A 89, 383 (1996).

10. R. Davies, Tribology-Theory and Practice, Arnold (2000).

11. AWS Welding Hand Book, Volume 3, 9th Edition, 113 (2004).

12. R. Tyagi, S.K. Nath and S. Ray, Mater. Sci. Tech. 20, 1 (2004). doi: $10.1179 / 026708304225012062$

13. R. Tyagi, S.K. Nath, and S. Ray, Metall. Mater. Trans. A, 33A, 1 (2002).

14. Y. Wang, L. Pan, and T. C. Lei, Wear 143, 57 (1991). 